\title{
HIERARQUIA DE MOEDAS E O PERFIL DOS FLUXOS DE CAPITAIS NO BRASIL (2000-2017)
}

\author{
Julio Cesar Nascimento ${ }^{1}$
}

\begin{abstract}
RESUMO: Com as alterações ocorridas no Sistema Monetário Internacional (SMI) com a quebra do regime de Bretton Woods em 1960/1970, abre uma discussão sobre a relevância do SMI atual para uma abordagem a relação centro-periferia. $\mathrm{O}$ atual regime monetário internacional, denominado de Dólar Flexível, se apresenta como uma dimensão especial para analisar a relação centro-periferia a partir da hierarquia de moedas. Essa hierarquia é baseada pela liquidez das moedas em âmbito internacional e se estrutura a partir do dólar no núcleo do sistema, seguida pelo o euro entre outras moedas centrais, e na base desse sistema estão as moedas periféricas. Essa hierarquia apresenta-se como problemática para os países de moedas periféricas, particularmente, quanto as vulnerabilidades, tais como: tendência de instabilidades na taxa de câmbio e taxa de juros e tendência especulativa, dentre outras. Nesse sentido, o trabalho tem como objetivo analisar um desses problemas para o Brasil na posição de moeda periférica, no regime dólar flexível, no período 2000-2017, particularmente, quanto ao perfil dos fluxos de capitais. A metodologia utilizada é bibliográfica, descritiva e explicativa de natureza quali-quantitativa com base de dados do Banco Central do Brasil (BACEN) com variáveis do Balanço de Pagamentos (BP).
\end{abstract}

Palavras-chave: Dólar Flexível; hierarquia de moedas; especulação; Brasil.

\section{HIERARCHY OF CURRENCIES AND THE PROFILE OF CAPITAL FLOWS IN BRAZIL (2000-2017)}

\begin{abstract}
With the changes that took place in the International Monetary System (SMI) with the break of the Bretton Woods regime in 1960/1970, it opens a discussion about the relevance of the current SMI for an approach to the center-periphery relationship. In the current international monetary regime called the Flexible Dollar, it presents itself as a special dimension to analyze the center-periphery relationship from the currency hierarchy. This hierarchy is based on the liquidity of currencies at an international level and is structured around the dollar at the core of the system, followed by the euro, among other central currencies and at the base of this system are peripheral currencies. This hierarchy presents itself as problematic for countries with peripheral currencies, particularly regarding vulnerabilities such as: instability trend in the exchange rate and interest rate and speculative trend, among others. In this sense, the work aims to analyze one of these problems for Brazil, in the position of peripheral currency, in the flexible dollar regime in the period 2000-2017, particularly, regarding the profile of capital flows. The methodology used is bibliographic, descriptive and

\footnotetext{
1 Doutorando em Desenvolvimento Econômico com ênfase em Padrões e Estratégias de Desenvolvimento pelo Instituto de Economia (IE) da Universidade Estadual de Campinas (UNICAMP) e Especialização em andamento em Direito Público, Mestre em Economia, Especialista em Ciência Política e Bacharel em Ciências Econômicas.
} 
explanatory of a qualitative and quantitative nature with a database of the Central Bank of Brazil (BACEN) with variables from the Balance of Payments (BP).

Keywords: Flexible Dollar, currency hierarchy, speculation, Brazil.

\section{INTRODUÇÃO}

Gonçalves et al. (1998), Fiori (2007), Tavares (1997), Tavares e Melin (1997), Fiori (2008) e Serrano (2007) mostram que no contexto internacional, o século XX passou por intensas transformações quanto às relações monetárias entre as nações. Desta forma, houve intensas mudanças no Sistema Monetário Internacional até a atualidade, como na transição do padrão-ouro para Bretton Woods até o regime atual, denominado por alguns autores de Dólar Flexível. Nessas mudanças, ocorreram alterações em meados da segunda metade do século $X X$, na qual, se intensifica o processo identificado de globalização, sobretudo a de cunho financeiro.

O estudo realizado por Palludeto e Abouchedid (2014) mostrou como Sistema Monetário Internacional (SMI), mais propriamente o sistema de Dólar Flexível, tiveram alterações relevantes. Em suas características, o regime denominado de dólar flexível tem o regime de câmbio flexível, com elevada mobilidade de capitais e impacto decisivo nas instabilidades do câmbio/juro. Para Palludeto e Abouchedid (2014), as relações monetárias entre as nações são hierarquizadas e têm impactos no grau de autonomia de políticas econômicas, assim, enfrentando problemas de outra esfera para as nações, principalmente, da periferia, como em instabilidades e restrições na autonomia de condução de política econômica.

Nesse intuito, este trabalho se concentra enquanto problematização: A posição internacional do Brasil enquanto moeda periférica no sistema Dólar Flexível culmina em problemas para o país, particularmente, nos seus fluxos de capitais? A partir dessa problematização, a hipótese utilizada: A posição do Brasil enquanto moeda periférica traz implicações para o país, particularmente, quanto ao perfil dos fluxos de capitais representados no BP, especificamente, quanto a sua natureza especulativa.

Assim, o trabalho tem como objetivo geral analisar os problemas para o Brasil na posição de moeda periférica no regime dólar flexível, no período 2000-2017, particularmente, quanto ao perfil dos fluxos de capitais. Desta forma, enquanto objetivos específicos têm-se: 1. Analisar a relevância da moeda em âmbito internacional, particularmente, o regime dólar flexível; 2. Analisar as implicações para 
os países de moedas periféricas dentro da hierarquia de moedas, numa perspectiva heterodoxa; 3. Avaliar os problemas para o caso brasileiro enquanto sua posição de moeda periférica, particularmente, no perfil dos fluxos de capitais.

Quanto aos aspectos metodológicos, o trabalho pode ser classificado como descritivo e explicativo e bibliográfico de natureza qualitativa e quantitativa. Os dados foram extraídos das séries temporais do Banco Central do Brasil. Os dados analisados são do BP no período 2000-2017. Além dessa introdução e considerações finais o trabalho é composto por mais três tópicos, quais sejam: 1. A relação centro-periferia no dólar flexível; 2. implicações da hierarquia de moedas e; 3. Análise do perfil do BP do Brasil no período 2000-2017.

\section{CENTRO - PERIFERIA NO DÓLAR FLEXÍVEL}

Existem diversas abordagens sobre hierarquia de moedas que serão tratadas, mesmo que superficialmente, porém, o trabalho parte da relevância da hierarquia a partir das formulações de Conti (2011), Conti et al. (2014), Palludeto e Abouchedid (2014) e de Fritz et al. (2006) sobre uma visão keynesiana-estruturalista com aspecto fundamental da globalização financeira, a discussão de Carneiro (2006) sobre a (in) conversibilidade da moeda, apontando a relevância da liquidez, dentre outros. Esses autores, em algum grau, tratam a hierarquia de moedas e a relação centro-periferia. Além disso, também tem uma discussão crítica sobre o assunto quanto as implicações, principalmente, para a periferia no SMI.

De acordo com Palludeto e Abouchedid (2014), para entender a dinâmica do centro-periferia, pós a quebra de Bretton Woods, é importante partir da análise da hierarquia monetária no cenário do Sistema Monetário Internacional atual marcado pela globalização financeira, desta forma, este trabalho adota essa abordagem para entender a relação centro-periferia na vertente da dimensão monetária internacional. Para entender a relevância do SMI atual baseado no Dólar Flexível é importante partir das diferenciações fundamentais em relação ao regime de Bretton Woods.

Quanto a esses pontos, têm-se que no regime Bretton Woods a moeda internacional era Dólar-ouro, com regime de câmbio fixo, porém ajustável e baixa mobilidade de capitais e com hierarquia de moedas com pouco impacto nas instabilidades do câmbio/juros. Já o regime contemporâneo, a forma de moeda 
internacional é o Dólar Flexível, com câmbio flexível e elevada mobilidade de capitais e quanto à hierarquia monetária tem impacto decisivo nas instabilidades câmbio/juros.

Desta forma, temos diferenças pertinentes para analisar o regime Dólar Flexível e, principalmente, a partir da hierarquia de moedas. Cabe ressaltar que alguns autores já estabeleciam, em algum grau, hierarquia de moedas em regimes anteriores, porém, no dólar flexível é relevante uma interpretação diferenciada tanto pelo formato diferenciado com o de Bretton Woods quanto pela a mudança no grau de hierarquia diferenciado do Padrão Ouro-libra.

Assim, essa hierarquia pode ser dinâmica e os fatores relevantes para Conti et al. (2014) são: condicionantes geopolítico e geoeconômico em âmbito mundial, desta forma, condicionantes meramente nacionais não tem elevado grau de peso no movimento da hierarquia monetária.

Hierarquia de moedas não é um assunto recente, Keynes (1930) já abordava a existência dessa hierarquia e que essa tinha implicações para o funcionamento das economias domésticas, principalmente, quanto à autonomia de política econômica entre os países credores e devedores no período entre a Primeira e Segunda Guerras Mundiais. Para entender essa dinâmica utiliza-se a proposta de hierarquia de moedas localizada na figura 01 .

Figura 1 - Hierarquia de Moedas

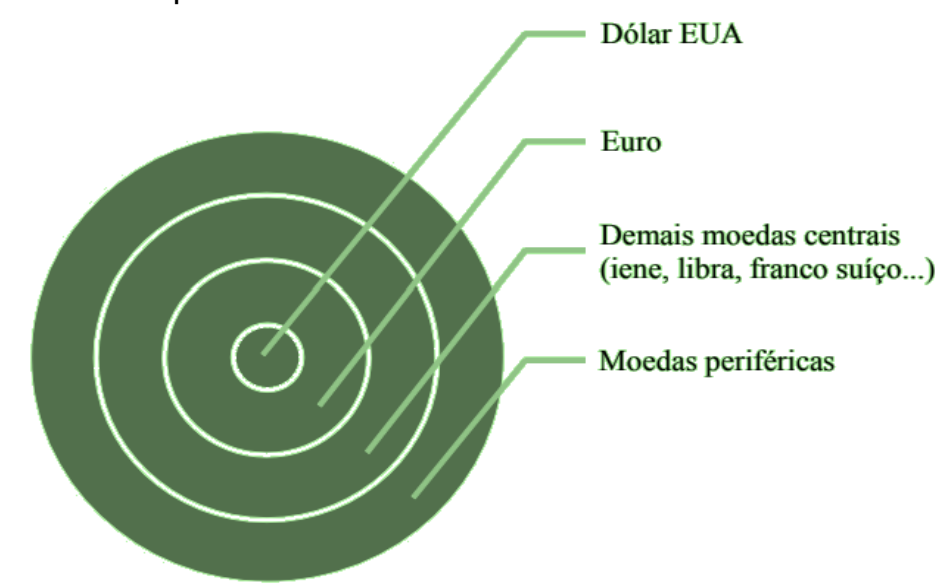

Fonte: Conti et al. (2014, p. 345)

Como mostra a figura 01, sobre a (in) conversibilidade da moeda, temos que, no núcleo do sistema são as moedas conversíveis, enquanto na parte mais externa dos níveis do ciclo, as moedas inconversíveis. Tratando essa perspectiva pela análise da hierarquia de moeda, tem-se que, as moedas do núcleo são dos países centrais 
enquanto as moedas mais distantes do núcleo são as dos países periféricos, ou seja, as moedas inconversíveis.

Sobre a hierarquia de moedas, Conti et al. (2014) apresentam que nesse sistema a moeda chave é o Dólar, depois o Euro como moeda subsequente da hierarquia e esta se diferencia das demais moedas, porém sem alcançar o status que o dólar tem no cenário internacional, depois do Euro tem-se as outras moedas centrais que tem função secundária no cenário internacional e, por fim, na última posição da hierarquia tem-se as moedas periféricas, que não exercem as funções adequadas no cenário internacional - "a não ser em caráter excepcional." (CONTI et al., 2014, p. 345).

Para Conti (2011), os determinantes dessa hierarquia são: poder geopolítico, instituições fortes e/ou favoráveis, o tamanho da economia nacional e a integração com a economia mundial, política econômica "responsável" e bons resultados macroeconômicos e voluntarismo político.

Para a literatura convencional, os fatores condicionantes dessa hierarquia são: unidade de conta, reserva de valor em âmbito internacional e meio de pagamento. Usando a proposta por Conti (2011), os determinantes da hierarquia vão além das três funções clássicas e podem ser definidas em seis funções: moeda reserva, moeda veicular, moeda de referência, moeda de denominação, moeda de investimento e financiamento e de intervenção, assim:

Além dessas seis funções, Conti (2011) avança numa discussão pertinente sobre a organização da hierarquia de moedas nessas funções. O autor trata os quesitos meio de pagamento (uso público e privado), reserva de valor (uso público e privado) e unidade de conta (uso público e privado). Nesses quesitos, o autor aponta o dólar como sendo predominante nas relações internacionais entre as nações, concluindo que o dólar está no núcleo do sistema seguida pelo euro e, por fim, as demais moedas, que em algum grau, desempenham funções no cenário internacional.

Além disso, essa relação tem diversos aspectos pertinentes, dentre esses, uma análise baseada na (in) conversibilidade da moeda. Carneiro (2006) propõe uma discussão sobre hierarquia apontando que a (in) conversibilidade da moeda é pertinente para analisar a posição da moeda em âmbito internacional.

Moeda conversível pode ser conceituada como sendo aquela que depende da sua aceitação no âmbito internacional e detém às funções clássicas de moeda 
internacional. Assim, nesse argumento não utiliza a identificação das demais funções da moeda internacional por Conti (2011).

A moeda inconversível pode ser identificada como aquelas que não tem aceitação no âmbito internacional e não possuem, enquanto características, as funções clássicas da moeda internacional. Parte-se aqui, que de acordo com a hierarquia de moedas adotadas nesse tópico, há diversos graus na hierarquia e assim de (in) conversibilidade.

Para Carneiro (2006), em primeira instancia, pode-se caracterizar que, em algum grau, as moedas conversíveis pela proposta desse trabalho são as moedas do centro da hierarquia e as moedas inconversíveis podemos identificar com as moedas da periferia do SMI. a inconversibilidade é permanentemente uma característica das economias periféricas (CARNEIRO, 2006). Para além do "pecado original", como proposta alternativa, tem-se a interpretação de carneiro (2006) baseada na (in) conversibilidade da moeda.

[...] Embora alinhando-se com a hipótese do original sin procura ir além e aponta para consequência mais profundas da inconversibilidade monetária num contexto de abertura financeira, tais como, as restrições ao aprofundamento financeiro e a não constituição de um sistema de financiamento de longo prazo e, o impedimento ao desenvolvimento de formas superiores de organização capitalista em razão da incapacidade da moeda local em desempenhar a função de instrumento de centralização de capitais na esfera financeira. Em suma, propugna-se um aprofundamento da noção de inconversibilidade monetária que transcende as implicações decorrentes do efeito riqueza e caminha na direção de considera-la como atributo essencial do subdesenvolvimento. (CARNEIRO, 2016, p. 2).

Além disso,

[...] A tese do pecado original parece ser uma explicação mais robusta ao apontar um elemento de bloqueio ao desenvolvimento dessa função nas moedas periféricas oriunda da ordenação do sistema monetário internacional, atribuindo à hierarquia de moedas o caráter determinante em última instância dessa atrofia. (CARNEIRO, 2006, p. 6).

Carneiro (2006) começa sua abordagem alternativa analisando a inconversibilidade da moeda quanto a incapacidade de ter a função clássica de reserva de valor em âmbito nacional e internacional. O argumento parte da análise do risco das diferentes moedas. A conclusão é que o dólar não tem prêmio de liquidez e está no núcleo do sistema, enquanto, as moedas periféricas que são essencialmente não conversíveis, além de serem identificadas dentro da hierarquia com taxa de juros 
com prêmio pela iliquidez (e demais prêmios adicionais) também aponta que esta é vítima do pecado original baseada nas restrições em endividamento em sua própria moeda (CARNEIRO, 2006).

Desta forma, algumas características podem ser descritas como sendo pertinentes para comprovação da inconversibilidade das moedas periféricas, tais como, a inexistência de cotações em âmbito internacional de mercadorias de moedas inconversíveis, não denominam ativos financeiros e nem como moeda de nominação de contratos (CARNEIRO, 2006).

\section{CONSIDERAÇÕES SOBRE AS IMPLICAÇÕES DA HIERARQUIA DE MOEDAS NO DÓLAR FLEXÍVEL}

Para Palludeto e Abouchedid (2014), uma das implicações desse poder é representado quanto ao grau diferenciado de autonomia para realização de políticas econômicas no centro e na periferia. Ou seja, o centro com maior autonomia enquanto a periferia com raio de manobra reduzido. As nações periféricas desse sistema enfrentam problemas de outra esfera, também diferenciado do sistema centroperiferia dos estruturalistas latino-americanos clássico. Assim, a hierarquia monetária é importante para o desempenho da economia doméstica.

De acordo com Palludeto e Abouchedid (2014), a hierarquia monetária tem alguns efeitos diferenciados sobre os países centrais e os periféricos, desde limitações em políticas cambiais, monetária e fiscal. Porém, acontece outros fenômenos baseados nas instabilidades dos juros e do câmbio inerente ao Sistema Monetária internacional contemporâneo, reduzindo a autonomia de políticas macroeconômica e restringindo a liberdade da utilização dos diversos instrumentos de intervenção econômica. Além dessas dimensões citadas, têm-se outros pontos importantes para a análise dessa nova relação centro-periferia baseada na dimensão monetária internacional.

A partir disso, para Cohen (1998), há um processo na qual as moedas do topo da pirâmide continuam reforçando a sua posição enquanto as moedas da base (periféricas) podem até ser substituídas. Conclui-se assim, que ocorre uma rígida pirâmide monetária, na qual, promove uma certa dificuldade de movimentações de moedas dentro da pirâmide. 
Para Palludeto e Abouchedid (2014), a liquidez é definitiva para analisar a hierarquia. Conti et al. (2014) faz uma discussão sobre a liquidez e uso da moeda no âmbito internacional como determinantes para analisar o grau diferenciado da hierarquia de moedas no SMI baseado no Dólar Flexível. Desta forma, o autor aponta que a hierarquia, em sua vertente da liquidez e uso da moeda nacional, tem impacto relevante nas variações do câmbio e dos juros e, por fim, em âmbito nacional sobre as políticas econômicas.

[...] Parte do uso internacional das moedas e da liquidez determinada por esse uso para tentar entender, justamente em função dessa liquidez (ou ausência de liquidez) internacional, qual o perfil da demanda por essas moedas e pelos ativos nelas denominadas. O caráter da demanda dos investimentos estrangeiros pelos ativos nacionais permite observar 0 comportamento dos fluxos de capitais que se direcionam a esses países e, por fim, seus impactos sobre as taxas de câmbio e juros e, consequentemente, sobre as políticas econômicas nacionais. (CONTI et al., 2014, p. 346).

Conti et al. (2014) usa como conceito de liquidez

[...] tem-se que liquidez internacional é a capacidade de um ativo de ser trocado, nas condições supracitadas, contra um meio de pagamento aceito em âmbito internacional. Por conseguinte, as moedas que exercem as funções da moeda nesse âmbito internacional são líquidas por definição, pois já são um meio de pagamento internacional e, sendo também unidade de conta e reserva de valor nesse mesmo âmbito possibilitam a conversão de moeda entesourada em poder de compor ou de liquidação de contratos sem gerar perda alguma (nem monetária, nem temporal). (CONTI et al., 2014, p. 347).

Desta forma, para Conti (2014) a liquidez é relevante para analisar a hierarquia e suas implicações. Neste caso, em âmbito internacional as moedas centrais têm liquidez mundial enquanto as periféricas não têm liquidez internacional. Portando, ativos denominados em moedas periféricas também tem liquidez reduzidas, trazendo assim, "os riscos de demora, custos ou mesmo perda de capital." para os detentores dos títulos em moedas periféricas (CONTI et al., 2014, p. 348).

Conti et al. (2014) usando o trade off de Hicks (1996) apresenta que as aquisições de ativos por parte dos agentes levam em consideração a liquidez e rendimento. Assim, tem-se que como as moedas periféricas, como abordado anteriormente, são ilíquidas ou com liquidez reduzida, os agentes procuram os ativos da periferia em casos de rendimentos elevados. 
Para Laplane (2016), a liquidez das moedas periféricas é cíclica e está atrelada ao ciclo de liquidez internacional. Nesse caso, no auge do ciclo há fluxos de capitais para as economias periféricas, buscando elevadas rentabilidades, e no momento que o ciclo muda tem-se uma reversão dos fluxos de capitais para as economias centrais. Desta forma, esses movimentos, em algum grau, apontam a liquidez reduzida da periferia do sistema. Além disso, tem-se uma diferença crucial entre moeda e divisa. Nesse caso, a divisa vai além das fronteiras nacionais. Para Aguietta (1986) divisas são as moedas que são aceitas internacionalmente.

A figura 02 mostra a liquidez dos ativos e demanda dos agentes em âmbito internacional, nesse esquema, há uma dimensão da hierarquia em nível internacional com distintas moedas, assim, os investidores podem decidir investir em distintos países. Para cima no caso da liquidez de ativos e para o lado liquidez de moedas. Nesse caso, para baixo e esquerda há liquidez maior baseado no dólar, por outro lado, quando direcionamos para cima e para a direita há liquidez menor.

Como sugere a figura 02, nos momentos de apetite pelo risco o fluxo se direciona para a iliquidez e quando se reverte para a liquidez, baseada, principalmente, no dólar como moeda chave desse sistema e, por diante, pelas moedas que são divisas internacionais, porém com grau de liquidez menor do que o dólar, como o euro. A partir dessa discussão a análise se direciona quanto aos impactos câmbio-juros.

Figura 2 - Liquidez dos ativos e demanda dos agentes - âmbito internacional

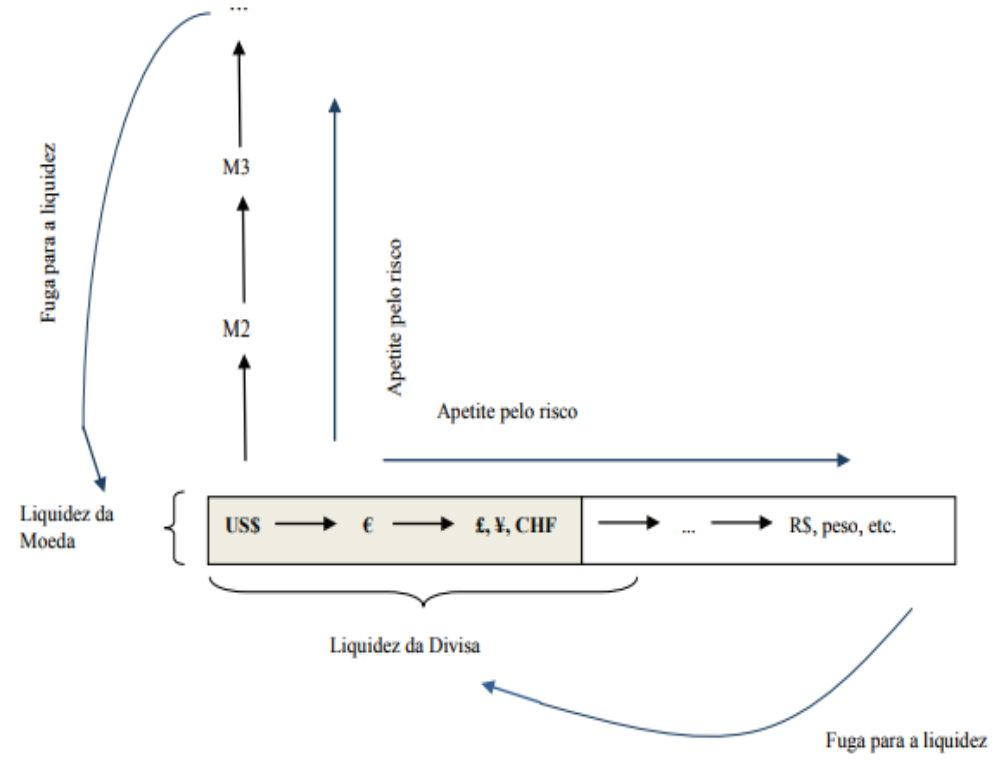

Fonte: Conti et al. (2014) 
Conti et al. (2014) busca uma interpretação a partir da discussão sobre a (i) liquidez interagindo com a taxa de juros, desta forma, partindo de Keynes (1936) que a taxa de juros remunera a iliquidez. Nesse caso, busca uma explicação para o fenômeno fazendo uma interação entre a teoria da paridade descoberta da taxa de juros (UIP) juntamente com a linha observado em Belluzo e Carneiro (2003) e Carneiro (2008), na qual, a taxa de juros nacional pode ser representada pela taxa de juros básica da economia mundial $\left(i^{\star}\right)$ - dólar -, risco-país (RP) - político e mercado-, variação cambial esperada (VC) e, por fim, prêmio pela iliquidez $(\mathrm{PI})$.

No caso da taxa de juros básica da economia mundial e prêmio pela liquidez há relevância da incerteza, têm impactos de questões estruturais e é determinada de forma exógena ao país. No caso do Risco-país e variação cambial esperada têm relevância o risco, têm impactos da formação conjuntural e é determinada de forma exógena e endógena.

Por esse processo, há uma necessidade de os países de moedas periféricas alocar as taxas de juros acima da moeda chave internacional, caso contrário, pode haver fugas de capitais e a atração de novos capitais para os países de moeda central, tornando assim, problemas na volatilidade cambial.

Pode-se concluir que com os esquemas que os países periféricos estão na margem desse sistema e que isso tem efeito nas taxas de juros domésticas, ou seja, na elevada taxa de juros para responder frente a sua iliquidez. Assim, precisando de mais prêmio para ter maior fluxos de capitais, porém, isso, além da rentabilidade tem efeito do apetite por risco dos investidores. Fazendo assim, no processo de reversão, haver uma fuga pela qualidade.

Para Fritz et al. (2016), quando há alterações nas políticas dos países centrais e/ou na preferência pela liquidez dos agentes em âmbito internacional, têm impactos nos países emergentes, pois, esses países têm dependência de fatores exógenos a suas competências domésticas.

Esses fluxos de capitais têm, em algum grau, um cunho especulativo para os países periféricos e contribui para a volatilidade cambial. Assim, no caso de um aumento da taxa de câmbio tem impacto na baixa demanda e, assim, depreciando mais a taxa de câmbio. Além disso, outros fatores alteram a taxa de câmbio como expectativa do mercado e variações na taxa de juros.

Como conclusão, para Conti et al. (2014) 
Percebe-se, então, que os países periféricos enfrentam dificuldades adicionais no manejo de sua política econômica que são raramente consideradas pela teoria econômica convencional. Em primeiro lugar, porque as taxas de câmbio tendem a ser voláteis, tornando a política cambial mais necessária, mas mais complexa de ser colocada em prática. Em segundo lugar, porque a política econômica nacional, em muitos desses países, estará implicada na luta contra essa - potencial - volatilidade cambial exacerbada, resultando na perda de autonomia da política econômica e, principalmente, da política monetária. Em terceiro lugar, porque, ainda que as taxas de juros não sejam utilizadas como instrumento de intervenção nas taxas de câmbio, elas são determinadas em parte por componentes exógenos ao país em questão, reduzindo a margem de manobra das autoridades monetárias domésticas. (CONTI et al., 2014, p. 366).

Laplane (2016) aponta que as consequências para os países periféricos pelo seu tipo de inserção nas finanças internacionais são: assimetrias financeiras, preços macroeconômicos e autonomia econômica. $\mathrm{O}$ autor faz uma crítica as teorias que abordam a abertura financeira com objetivo de melhorar a eficiência na alocação dos recursos internacionais, em termos genérico, da ideia de convergência em âmbito internacional dos recursos. A crítica direcionada a essas teorias é que essas negligenciam os movimentos especulativos em âmbito internacional (LAPLANE, 2016).

Quanto a assimetria financeira, que tem como condicionante relevante o tipo de inserção periférica no sistema monetário e financeiro internacional, impacta em assimetrias macroeconômicas (LAPLANE, 2016).

\begin{abstract}
O maior grau de autonomia econômica corresponde ao país emissor da moeda-chave, os Estados Unidos, é mais limitado para o resto dos países centrais, e mais estreito nos países com moedas periféricas, agravado, particularmente, nos países afetados pela substituição monetária. Por sua vez, a instabilidade intrínseca do SMFI tem impactos ainda mais adversos sobre os países periféricos, pois apresentam uma maior volatilidade potencial dos preços-chave, com destaque para a taxa de câmbio e a taxa de juros, em função de suas peculiaridades (LAPLANE, 2016, p.12).
\end{abstract}

Fritz et al. (2016) também discute as limitações das políticas econômicas, numa perspectiva keynesiana, aos países emergentes, partindo da hierarquia de moedas na globalização financeira, especificamente, sobre a política monetária e cambial. Quanto à política cambial, tem-se que com a volatilidade cambial em um ambiente de livre mobilidade de capitais reforça ainda mais o caráter de restrição a autonomia de política econômica dos países emergentes. Assim, de acordo com Flassbeck (2001) 
apud Fritz et al. (2016) a volatilidade cambial traz problemas macroeconômicas como na fragilidade financeira, no crescimento e inflação.

Quanto à política monetária, os autores também apontam que o Regime de Metas de inflação (RMI), adotadas em muitos países periféricos, na década de 1990, contribui como um inibidor de autonomia de política econômica para os países emergentes. Nesse caso, o RMI tem foco no uso da política monetária para combater inflação (FRITZ et al., 2016).

Assim, as discussões sobre RMI, apontam que, os países que adotam esse sistema perdem autonomia para usar instrumentos de política monetária para outros intuitos macroeconômicos, como crescimento econômico e emprego. Quanto a discussão sobre (in) conversibilidade do tópico anterior

\footnotetext{
A hierarquia de moedas no ambiente contemporâneo pode se revelar ainda mais perversa para os países periféricos emissores de moedas nãoconversíveis, dadas as características do sistema monetário internacional após o colapso do acordo de Bretton Woods, em 1971-1973. (PRATES; CINTRA, 2007, p. 10).
}

Assim, conclui-se que há uma limitação das autoridades de políticas econômicos nos países periféricos de realizar políticas econômicas.

\section{A PROBLEMÁTICA DOS FLUXOS DE CAPITAIS NO BRASIL: UMA ANÁLISE A PARTIR DO BALANÇO DE PAGAMENTOS}

O argumento na fundamentação teórica é que países de moedas periféricas têm tendência a ter maior investimentos especulativos. Desta forma, nesse ponto é relevante fazer uma análise do BP. A análise parte de uma visão geral do BP com as transações correntes (Balança comercial e de serviços, rendas primárias, rendas secundárias), conta capital, conta financeiras (Investimento direto, investimento em carteira, derivativos, outros e ativos reservar) e erros e omissões no período entre 2000-2017.

Para aprofundar as discussões sobre ambiente especulativo abre-se uma ênfase para o investimento direto e investimento em carteira e rendas primárias com suas subcategorias, principalmente, quanto a renda de investimento. $\mathrm{O}$ gráfico 01 mostra os grandes componentes do BP entre o período 2000-2017 em milhões de dólares por ano. Os grandes componentes do BP são as transações correntes, conta capital, conta financeira e erros e omissões 
Durante todo o período, os componentes da conta capital e erros e omissões tiveram o menor impacto no BP mantendo-se na tendência e variando entre saldos positivos e negativos. Quanto as transações correntes e conta financeira, passaram por intensas instabilidades e com os resultados anuais, em grande parte do período, negativos. Porém, tiveram impactos mais relevantes no BP. Esses dois itens serão detalhados durante o trabalho.

A conta capital não passou por grandes alterações quando comparada com as transações correntes e conta financeira. Com exceção de 2004 que teve o resultado negativo em -213.1 milhões de dólares, os demais anos mantiveram-se com saldos positivos e com a mesma tendência. O maior resultado dessa variável foi em 2015 quanto o saldo fechou em 416,2 milhões de dólares. Quanto aos erros e omissões, houve variações entre saldos negativos e positivos. Porém, não passou por intensas mudanças, como as transações correntes e conta financeira. O maior resultado desse componente ocorreu em 2015 com 23.827,9 e o pior em 2007 com -3.152,10. Quando comparado com as transações correntes e conta financeira essa variável não tem tanto impacto no BP.

As transações correntes, entre 2000-2017, obtiveram valores de déficit na maioria dos períodos analisados. Os saldos positivos ocorreram entre 2003 a 2007, ou seja, durante 5 anos dos 18 anos analisados. O melhor resultado de superávit registrado ocorreu em 2005, com saldo de $13.547,20^{2}$ milhões de dólares, enquanto o pior resultado de déficit ocorreu em 2014, onde registrou -104.181,90 milhões de dólares.

Assim, as transações correntes alternaram entre período de déficits e superávits ocorrendo entre 2000-2002 déficit, 2003-2007 superávit e, por fim, déficit entre 2008-2017. Por fim, o resultado da conta financeira que engloba os investimentos diretos, investimento em carteira como principais componentes do seu resultado seguiu a mesma trajetória das transações correntes, porém, já em 2007 esta registrou saldo negativo, enquanto a das transações correntes em 2007 ainda se mantiveram superavitárias. A conta financeira registrou o melhor saldo 13.115,20 em 2006 e o pior em 2013 com -100.598,50, na qual, juntamente com as transações

2 Todos os valores do BP entre 2000-2017 estão detalhados entre os anexos 08 a 16 . 
correntes iniciaram um período de redução dos saldos negativos, mantendo essa tendência até 2017.

Gráfico 1 - Componentes do Balanço de Pagamentos no Brasil- anual - milhões de dólares 2000/2017

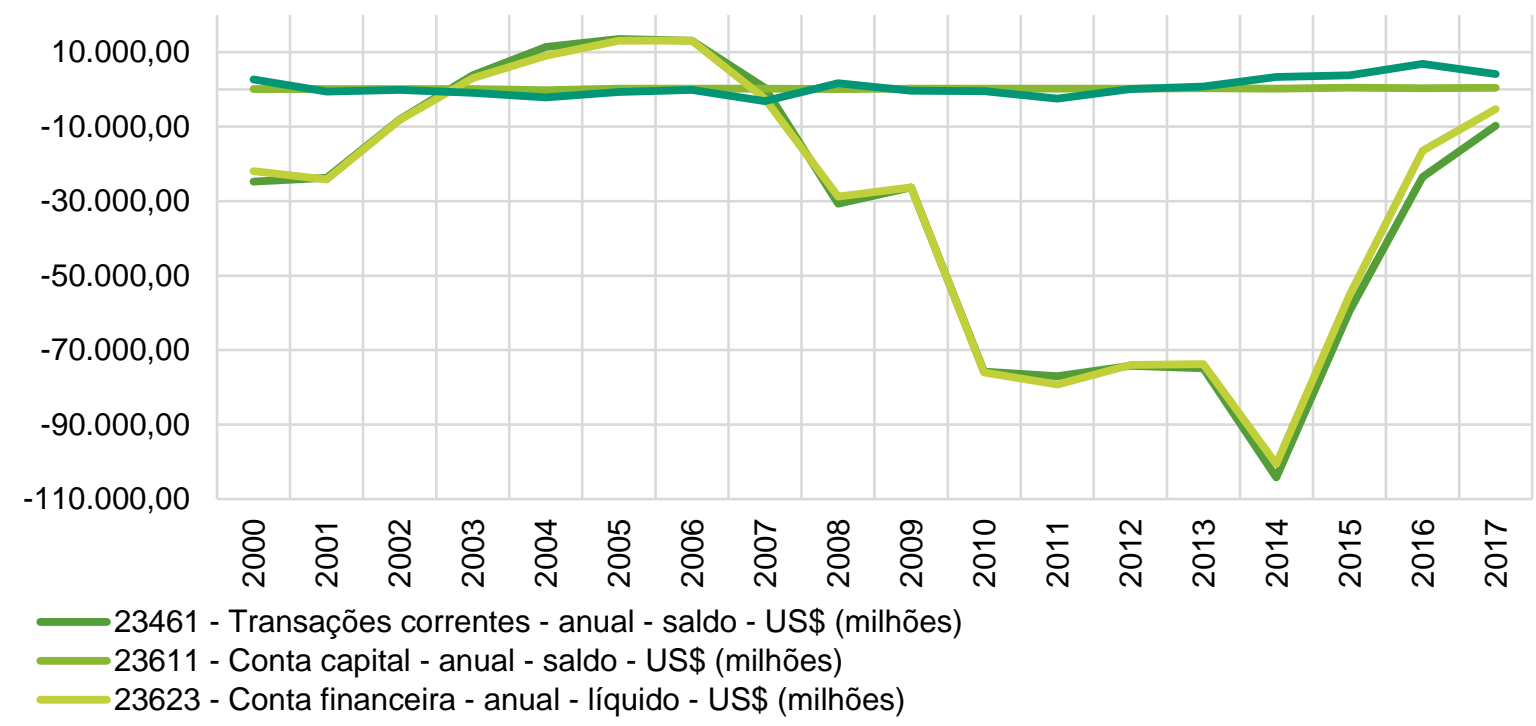

Fonte: elaboração própria com dados extraídos do BCB

Em síntese, em 2000 inicia-se uma tendência de redução dos saldos negativos até o saldo se tornar positivo no ano de 2003, com extensão desse saldo positivo até 2006. A partir de 2008, os saldos se tornaram negativos e aprofundando nessa tendência negativa com seu pior resultado em 2014 que é quando inicia-se uma tendência de redução dos saldos negativos até 2017, onde registrou saldo de $-9.761,8$ nas transações correntes e $-5.230,30$ na conta financeira.

Desta forma, os componentes do BP tiveram intensos movimentos e os que mais influenciaram foram as transações corrente e conta financeira. Essa dinâmica teve elevada influência das variações dos preços em âmbito internacional dos produtos que o Brasil produz e a conjuntura para os investidores. Quanto a conta financeira, tem enquanto subcomponentes o investimento direto e investimento em carteira como principais influenciadores do resultado dessa variável. Pelos objetivos desse trabalho há relevância quanto análise comparativa do investimento direto e, principalmente, investimento em carteira.

O gráfico 02 mostra a conta financeira e seus dois subcomponentes, investimento direto e investimento em carteira, entre o período 2000-2017. Os investimentos diretos e investimentos em carteira apresentaram uma tendência muito 
próxima. Entre 2000-2006 houve uma tendência de melhora no resultado da CF. Porém, a partir de 2007 esse quadro começou com uma tendência de pioria até 2014. Em 2015 inicia-se um período de melhora nos saldos, esta tendência teve saldo positivo na conta carteira a partir de 2016 seguindo a mesma tendência para o ano seguinte.

Quanto ao investimento direto externo o pior resultado foi em 2011, o saldo fechou em -79.242,2 milhões de dólares e o melhor resultado em 2006 com 9.380,3 milhões de dólares, na qual, foi o único ano que o investimento direto ao país foi superior ao investimento direto no exterior. Assim, com exceção de 2006 em todos os períodos (2000-2017) os investimentos do Brasil no exterior superaram aqueles realizados do exterior no Brasil. $O$ investimento em carteira obteve resultados negativos na maioria dos períodos analisados com exceção de 2002, 2004, 2016 e 2017 com resultados variando de -66.913,00 milhões de dólares em 2010 a 19.216,40 em 2016.

Gráfico 2 - Conta financeira e seus componentes principais no Brasil - anual - milhões de dólares 2000/2017

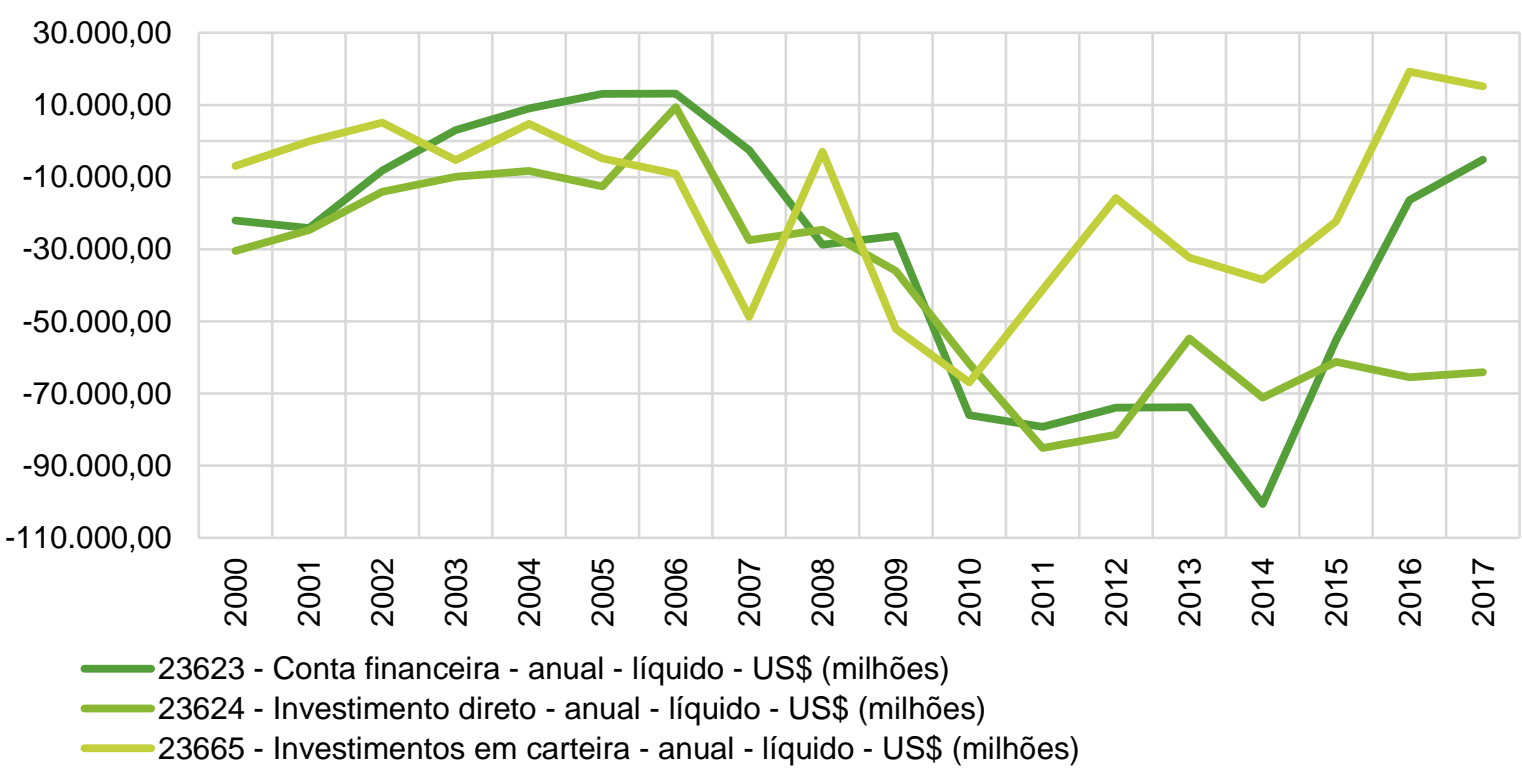

Fonte: elaboração própria com dados extraídos do BCB

Desta forma, conclui-se que o investimento em carteira e direto tiveram uma tendência muito próxima, culminando, em elevado grau, o resultado total da conta financeira. Nesse caso, a conta carteira será detalhada no próximo gráfico para fim de análise sobre a tendência especulativa. Para método de análise, considera-se que 0 
investimento em carteira é, em média, com intuito de rentabilidade de curto prazo. Diferentemente do investimento direto que é um investimento que tem impactos direto na economia e com prazo de maturação. O investimento em carteira pode ser apenas para especular a taxa de juros em um período curto, este, representa, no geral, investimento sem grande impacto produtivo.

O gráfico 03 mostra o investimento em carteira que é dividida em dois subcomponentes: os ativos e os passivos. Enquanto resultados, tem-se que, tanto os ativos quanto os passivos passaram por instabilidades, principalmente, a partir de 2006. Porém, as instabilidades dos ativos foram menores que a dos passivos. Temse que no geral os passivos, ou seja, as obrigações do investimento em carteira, culminaram com maior intensidade no resultado do investimento em carteira. Quanto aos ativos, tem-se que o pico e a base das variações foram 16.855,5 milhões de dólares em 2011 e em 2017 com 14.062,5 milhões de dólares e enquanto os passivos em 2010 com 71.648,10 milhões de dólares e -19.815,00 milhões de dólares em 2016.

Gráfico 3 - Componentes do investimento em carteira no Brasil - anual - milhões de dólares 2000/2017

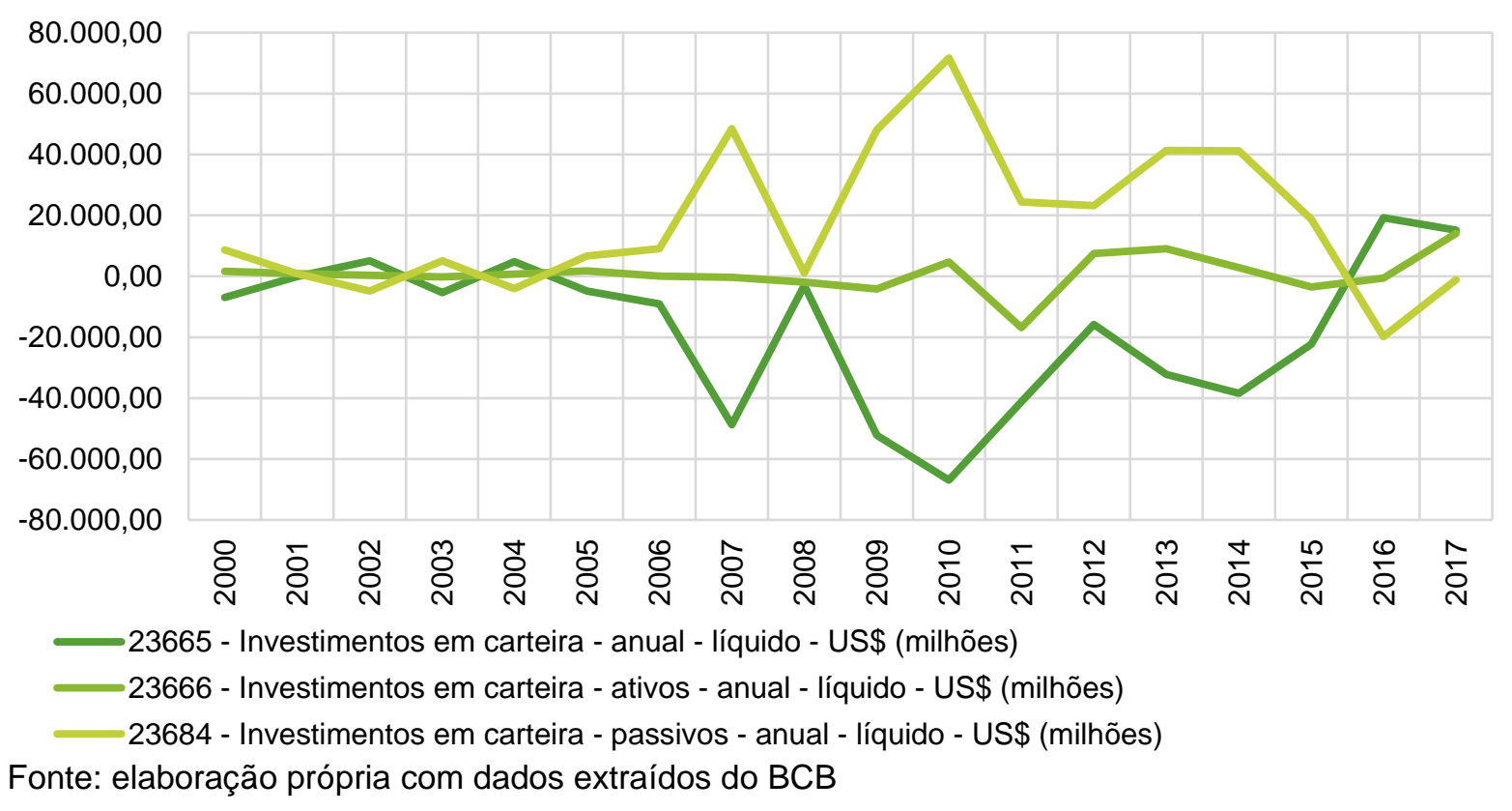

Conclui-se que o investimento em carteira teve uma tendência de intensas variações dos ativos e passivo, porém, a intensidade das variações dos passivos foi maior. Além da tendência especulativa do lado do investimento pela conta financeira, tem-se que essa pode ser também observada quando analisada pelas transações 
correntes pela via das rendas primárias, principalmente, quanto ao seu subcomponente rendas de investimento em carteira.

Gráfico 4 - Transações correntes e seus componentes no Brasil - anual - milhões de dólares 2000/2017

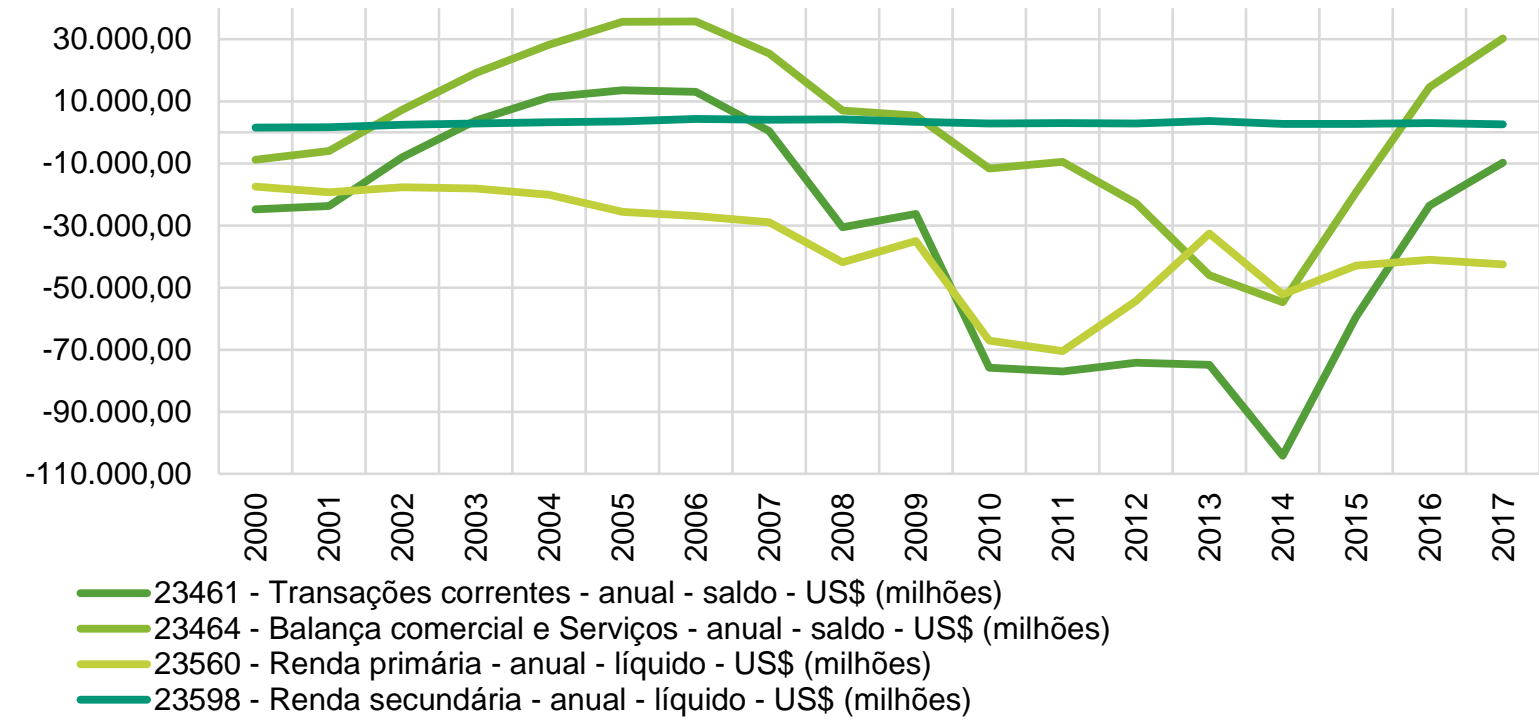

Fonte: elaboração própria com dados extraídos do BCB

O gráfico 04 mostra os resultados das transações correntes e seus componentes, quais sejam: balança comercial e serviços, renda primária e renda secundária. A balança comercial e de serviços juntamente com a renda primária foram as que mais exerceram impacto sobre o resultado das transações correntes durante 2000-2017, enquanto a renda secundária durante o período teve pouco impacto nas transações correntes, porém, mantendo-se na mesma tendência e com resultados sempre positivos.

A balança comercial e de serviços seguiu a mesma tendência geral do saldo das transações correntes. Esse subcomponente passou por uma tendência de aumento do saldo até 2005, onde a partir de 2016 inicia-se um processo de redução até ter expressão negativa em 2010 e continuando com saldos negativos até 2015 . Porém, em 2016-2017, houve saldo positivo no subcomponente balança comercial e de serviços. Quando se divide a balança comercial e de serviços tem-se que o saldo dos serviços sempre foram negativos, enquanto o da balança comercial quase sempre positivo com exceção de 2000 e 2014. Desta forma, as transações com serviços impactaram negativamente no saldo da balança comercial e serviços enquanto a 
balança comercial, na maioria dos períodos, culminava no saldo positivo desse subcomponente.

Dos subcomponentes das transações correntes o mais relevante para 0 presente trabalho é o da renda primária. O subcomponente teve registros negativos durante 2000-2017 e com impactos significativos. O pior resultado ocorreu em 2011 com -70.475,00 milhões de dólares. Quanto a tendência da renda primária, esta ocorreu de forma linear até 2007, ou seja, sem grandes variações. Porém, a partir de 2010 esta começa a deteriorar até 2011 onde já no ano seguinte tem-se melhoras até 2017, mas sempre com resultados negativos.

Para os objetivos desse trabalho será relevante afunilar na análise da renda primária.

Gráfico 5 - Renda primária e seus componentes no Brasil - anual - milhões de dólares - 2000/2017

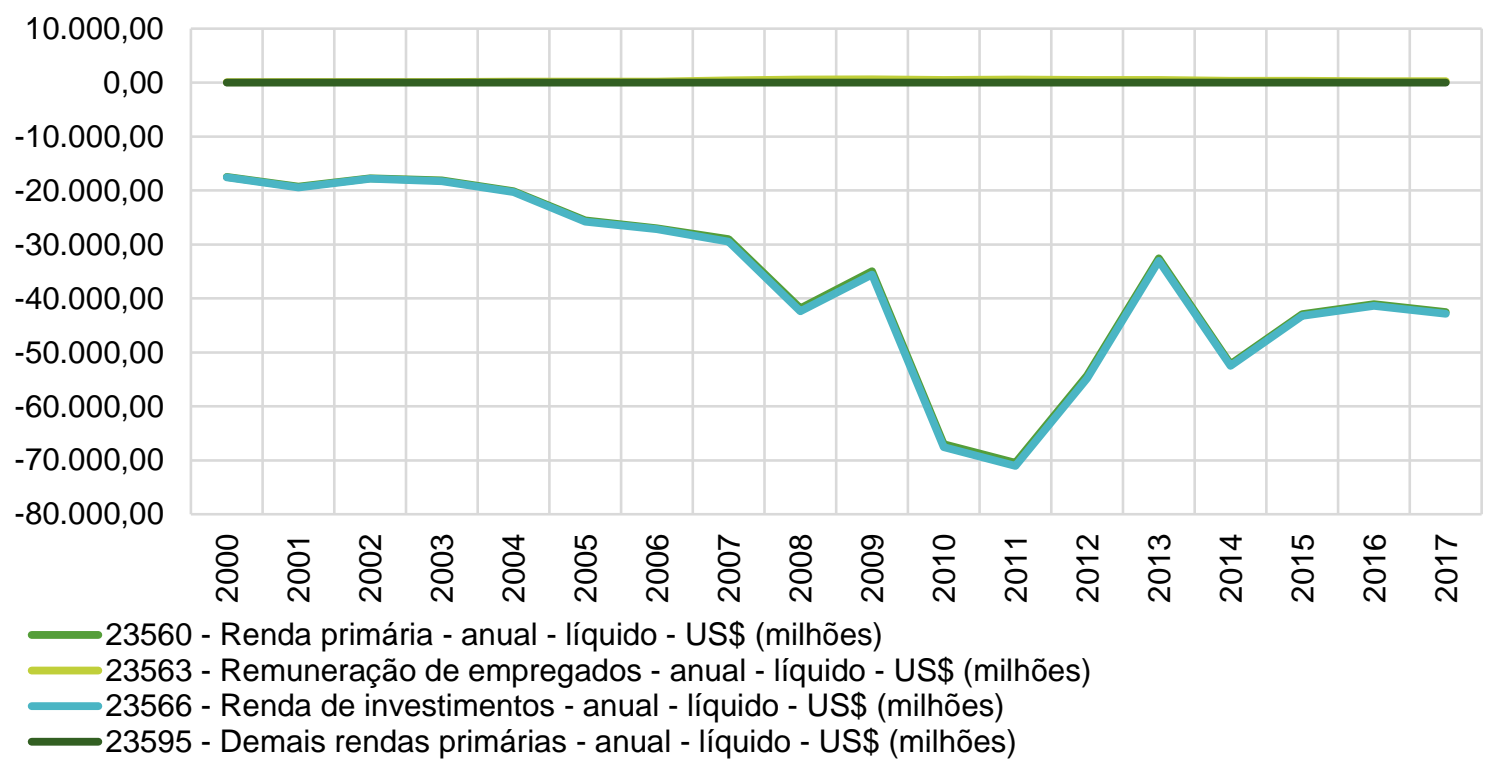

Fonte: elaboração própria com dados extraídos do BCB

A renda primária tem como subcomponentes a remuneração de empregados, renda de investimento e demais rendas. O gráfico 05 mostra a tendência desses componentes entre 2000-2017 no Brasil. Nesse caso, tem-se que a remuneração de empregados e demais renda não tiveram impactos tão significativos do resultado final da renda primária, principalmente, quando comparada ao subcomponente renda de investimento. 
A remuneração de empregados e demais tenda primária mantiveram-se na mesma tendência durante todo o período analisado e com resultados muito próximos, assim, teve uma tendência linear.

Quanto a renda de investimento, apresentou-se como o maior impacto e decisivo no resultado final da renda primária durante 2000-2017. Entre 2000-2004 não ocorreram grandes mudanças no resultado da renda de investimento. Porém, a partir de 2005 essa variável inicia-se um período de mudanças intensas durante os anos, onde, obteve seu pior resultado em 2011 com -71.041,6 milhões de dólares.

Cabe uma análise sobre os componentes da renda de investimento que é dividida entre renda de investimento direto, renda de investimento em carteira e renda de outros investimentos (juros). O gráfico 06 mostra o resultado dos componentes da renda de investimento.

Gráfico 6 - Renda de investimentos da renda primária das transações correntes no Brasil - anual milhões de dólares - 2000/2017

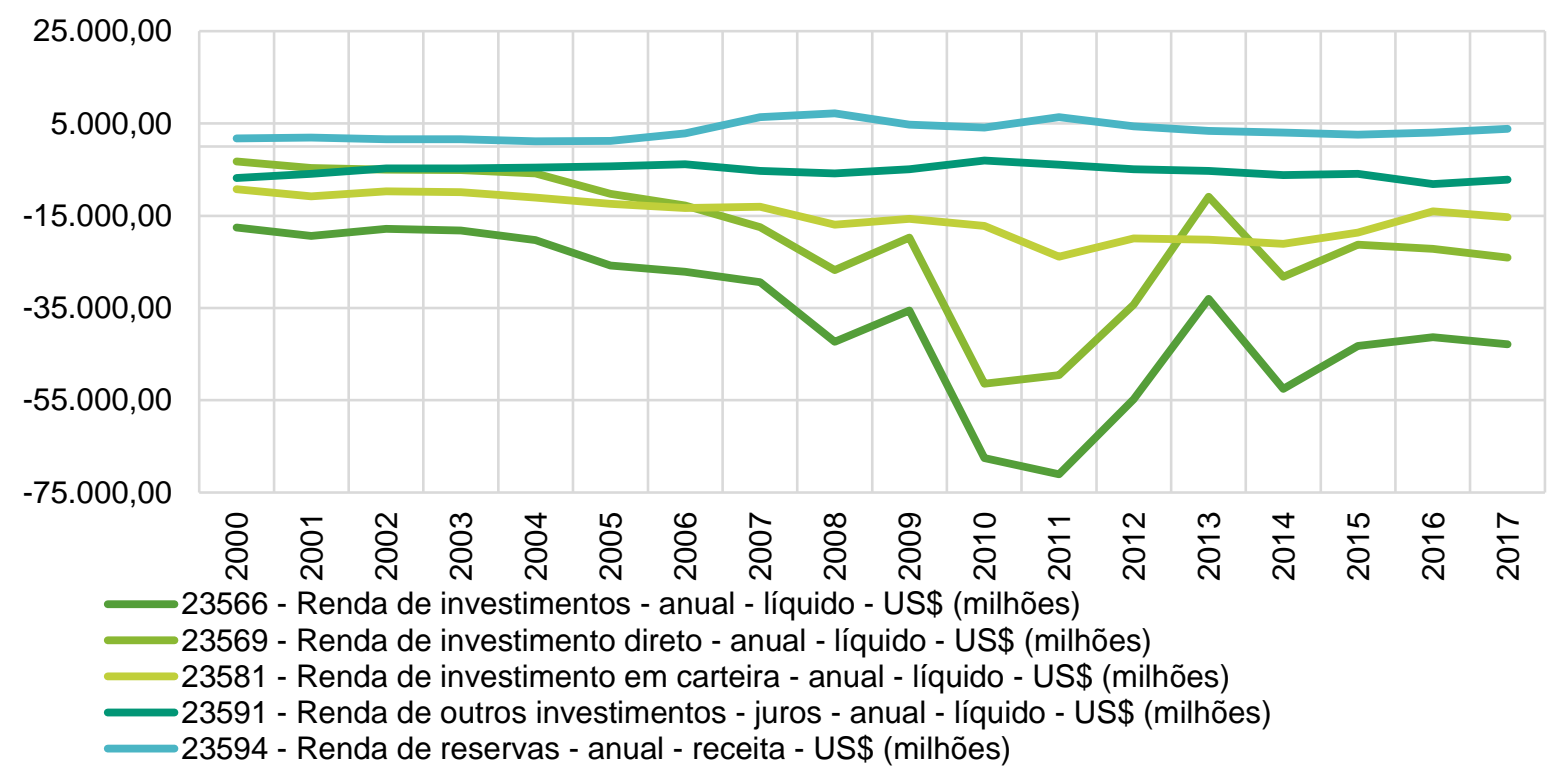

Fonte: elaboração própria com dados extraídos do BCB

Quanto ao resultado da renda de investimento, a renda de reservas e de outros investimentos (juros) mantiveram na tendência sem grandes alterações relevantes, principalmente, quando comparado com a renda de investimento direito e investimento em carteira. A renda de reservas registrou nenhuma transação durante todo o período analisado enquanto a renda de remuneração de empregados teve registros com resultados sempre positivos. 
Por outro lado, a renda de investimento externo e carteira registraram a mesma tendência entre 2000-2006 e, a partir de 2007, o investimento direito registrou uma tendência de aprofundamento do déficit até 2010. A partir de 2011 inicia-se um processo de redução desses saldos negativos até 2017. O pior resultado da renda de investimento direito ocorreu em 2010 com 51.409,9 milhões de dólares.

O investimento em carteira entre 2010 a 2017 passou por mudanças nos valores, porém, não tanto quanto o do investimento direto. O pior registro dessa conta ocorreu em 2011 com -23.881,80 milhões de dólares.

\section{CONSIDERAÇÕES FINAIS}

O presente trabalho teve como objetivo analisar os problemas para o Brasil na posição de moeda periférica no regime dólar flexível no período 2000-2017, particularmente, quanto o perfil do BP. A literatura aponta que no regime Dólar Flexível há uma hierarquia de moedas, ou seja, moedas que são centrais e outras periféricas nas relações internacionais, ou seja, com e sem liquidez, assim, impactando em relações assimétricas em âmbito internacional entre os países, inclusive, na economia doméstica.

Esse sistema impacta em diferentes graus de autonomia para realizar política econômica no centro e na periferia. Assim, a periferia com baixo raio de manobra para realizar política econômica. Por outro lado, há um elevado grau de autonomia de política econômica para os países centrais, principalmente, para os EUA que tem a moeda chave do núcleo do SMI. Desta forma, há uma retroalimentação e manutenção da posição de moedas periféricas e centrais.

Para os países de moedas periféricas como o Brasil a literatura aponta instabilidades na taxa de câmbio e na taxa de juros observadas, principalmente, nos ciclos de liquidez em âmbito internacional. Além disso, o perfil dos investimentos internacionais no Brasil é de cunho mais especulativo, no geral. É sobre os fluxos de capitais que esse trabalho contempla com uma análise empírica.

$\mathrm{Na}$ análise do BP tem-se que as transações correntes e conta financeira tiveram os maiores impactos sobre o saldo total do BP. Estas variáveis tiveram tendência parecidas, enquanto a conta capital e erros e omissões tiveram pouco impacto no BP e com tendência próxima, porém, diferentes das transações correntes e conta financeira. 
A conta financeira teve o maior impacto do investimento direto e do investimento em carteira, apontando a significância do investimento em carteira para a composição de uma tendência maior desse tipo de investimento. Nas transações correntes os que tiveram maior impacto desse lado do BP foram a balança comercial e serviços juntamente com a renda primária. No caso da balança comercial e serviços ambos tiveram impactos, porém os serviços com registros sempre negativos e o comercial na maioria do período analisado com saldo positivo, ou seja, em termos de milhões de dólares as exportações alcançaram resultados maiores que as importações.

No caso da renda primária, o subcomponente com maior significância foi a renda de investimento, principalmente, do investimento direto e investimento em carteira. No caso do investimento em carteira, todos os subcomponentes tiveram impacto relevante na conta, ou seja, dos lucros e dividendos, lucros e títulos negociados no mercado externo e interno.

Desta forma, quanto a questão da tendência especulativa, considerando os investimentos em carteira como sendo, em algum grau, de prazo reduzido e improdutivo quando comparado ao investimento direto, teve uma tendência de maior significância ao longo do tempo, este resultado pode-se confirmar pelo lado da renda primária onde passou a ter significância principalmente da renda do investimento em carteira ao longo do tempo.

\section{REFERÊNCIAS BIBLIOGRÁFICAS}

ARRIGHI, G. O Longo Século XX. Rio de Janeiro: Contraponto, 1994.

BATISTA, P. N. O CONSENSO DE WASHINGTON: A visão neoliberal dos problemas latino-americanos. 1994. Disponível em:

http://www.consultapopular.org.br/sites/default/files/consenso\%20de\%20washington. pdf. Acesso em: 26/11/2017

BAUMANN, R; CANUDO, O; GONÇALVES, R. Economia Internacional Teoria e Experiência Brasileira. Rio de Janeiro: Campus, 2004.

BELLUZZO, L. G. de M.; CARNEIRO, R. O mito da conversibilidade. Revista de Economia Política, São Paulo: Editora 34, v. 24, n. 2, p. 218-222, abr.jun. 2004. BIELSCHOWSKY, R. Cincuenta años del pensamiento de la CEPAL: una reseña. Em Cincuenta años de pensamento em la CEPAL. Textos seleccionados, vol. 1, Fondo de Cultura Económica, CEPAL, Santiago, Chile, 1998. 
BRESSER-PEREIRA, L. C.; GALA, P. Structuralist development macroeconomics. Brazilian Journal of Political Economy, v. 30, n. 4, p. 663-686, 1 Oct. 2010.

\section{CARAMES, L. A, ESTRUTURAS DE PODER, REGULAÇÃO FINANCEIRA E} CRISE: Economia Política Internacional da regulação financeira no pós-crise 2007/2008. Dissertação (Mestrado em Economia Política Internacional), Instituto de Economia, Universidade Federal do Rio de Janeiro, Rio de Janeiro, 2016. Disponível em: http://www.ie.ufrj.br/images/pos-

graducao/pepi/dissertacoes/mestrado/2016/lucas_de_almeida_carames_ca8e3.pdf , acesso em: 18/09/2017.

CARNEIRO, R. Globalização e inconversibilidade monetária. Texto para Discussão. CAMPINAS: IE/UNICAMP n. 120, abr. 2006. Disponível em:

http://centrocelsofurtado.com.br/arquivos/image/201108311529260.CARNEIRO4.pdf , acesso em : 18/09/2017.

CARNEIRO, R. O Dólar e seus Rivais. Observatório da Economia Global, textos avulsos - no.1 - Abril, 2010.

CASTELI, J.R. A ascensão da China e a contestação do Dólar após a crise financeira global. 2015. Disponível em:

https://www.anpec.org.br/encontro/2015/submissao/files_l/i7db657db014e3a564f5a9573d3bd37137.pdf , Acesso em 17/07/2017.

CHINN, M.; FRANKEL, J. (2008). The euro may over the next 15 years surpass the dollar as leading international currency. NBER Working Paper No. 13909

COHEN, B. J. The geography of money. Ithaca: Cornell University Press, 1998.

CONTI, B.M. Política Cambial e Monetária: os dilemas enfrentados por países emissores de moeda periféricas. Tese (Doutorado em Economia), Instituto de Economia, Universidade Estadual de Campinas, Campinas, 2011.

CONTI, B. M.; PRATES, D. M.; PLIHON, D. A hierarquia monetária e suas implicações para as taxas de câmbio e de juros e a política econômica dos países periféricos. Economia e Sociedade, Campinas, v. 23, n. 2, p. 341-372, Aug. 2014.

DE CECCO, Marcello. Money and Empire. The International Gold-Standard, 1890-1914. Basil Blackwell: Oxford. 1974

DIAS, M. F. Do Estruturalismo da CEPAL à Teoria da Dependência: continuidades e rupturas no estudo do desenvolvimento periférico. Dissertação (Mestrado em Ciência Política), Universidade de São Paulo, São Paulo, 2012.

EICHENGREEN, B. Globalizing capital: a history of the international monetary system. Princeton: Princeton University Press, 2000.

EICHENGREEN, B. História e reforma do sistema monetário internacional. Economia e Sociedade, Campinas, v. 4, n. 1, p. 53-78, 2016. 
EICHENGREEN, B. The Renminbi as na international currency. Journal of policy modeling: A social Science forum of world issues, New York, v.33, n. 5, p. 732730 Bimensal. Publicada pela Elsevier para Society for policy modeling.

FIORI, J. L. O Poder Global e a Nova Geopolítica das Nações. São Paulo: Boitempo, 2007.

FIORI, J. L. O sistema interestatal capitalista no início do século XXI. O Mito do Colapso do Poder Americano. Rio de Janeiro: RECORD, 2008.

FIORI, J. L. O poder Americano. Petrópolis: Editora Vozes, 2007.

FIORI, J. L. MEDEIROS, C. SERRANO, F. O Mito do Colapso do Poder Americano. Rio de Janeiro: RECORD, 2008.

FRITZ, B. PAULA, L. F, PRATES, D. M. Hierarquia de moedas e redução da autonomia de politica econômica em economias periféricas emergentes: uma análise keynesiana-estruturalista. Keynes: Ensaios sobre os 80 Anos da Teoria Geral. Porto Alegre: Tomo Editorial, 2016, p. 177-202. Disponível em: http://www.luizfernandodepaula.com.br/ups/hierarquia-de-moedas-e-reducao-daautonomia-de-politica-economica.pdf , acesso em : 18/09/2017.

FURTADO, C. Teoria e Política do Desenvolvimento Econômico. São Paulo: Abril Cultural, 1983.

FURTADO, C. Um projeto para o Brasil. Rio de Janeiro: Editora Saga, 1968.

GIL, A. C. Como elaborar projetos de pesquisa. 4 ed. São Paulo: Atlas, 2002.

GONÇALVES, R. PRADO, L. C. D. BAUMANN, R. CANUDO, O. A Nova Economia Internacional: Uma Perspectiva Brasileira. Rio de Janeiro: Campus, 1998.

GONTIJO, C. OS MECANISMOS DE FUNCIONAMENTO DO "PADRÃO-OURO": UMA VISÃ̃o CRÍTICA. Textos para discussão 435, CEDEPLAR, UFMG, 2011.

LAPLANE, E. G. HIERARQUIA DE MOEDAS E SOBERANIA MONETÁRIA: Uma primeira aproximação. In: ANPEC, 2016. Disponível em:

https://www.anpec.org.br/encontro/2016/submissao/files_l/i7-

eee4fa1bd86ad67c66ca6e418af98471.pdf , acesso em: 18/09/2017.

KEYNES, J. M. (1930). Treatise on money, v. 2 - The applied theory of money. The Collected Writtings of John Maynard Keynes, v. VI. London: MacMillan, 1971.

KEYNES, J.M. The General Theory of Employment, Interest, and Money. London: Palgrave Macmillan, 1936.

KRUGMAN, P. R. (1984) The International Role of the Dollar: Theory and Prospect. In: BILSON, J. F. O.; MARSTON, R. C. Exchange Rate Theory and 
Practice. Chicago: University of Chicago Press, Cap. 8. p. 261-278. (ISBN: 0-22605096-3).

MARCONDES, R. L. Padrão-Ouro e Estabilidade. EST. ECON., SÃO PAULO, V. 28, N. 3, P. 533-559, 1998.

MIAGUTI, C.Y. A ascensão do dólar e a crise do padrão ouro-libra (1913-1931). Dissertação (Mestrado em Economia Política Internacional), Instituto de Economia, Universidade Federal do Rio de Janeiro, Rio de Janeiro, 2016.

MELLO NETO, M. R; ARAÚJO, V. L. Instabilidade Internacional e Hegemonia: notas sobre a evolução do Sistema Monetário Internacional. Textos para discussão, Universidade Federal Fluminense, Rio de Janeiro, 2006. Disponível em: http://www.uff.br/econ/download/tds/UFF_TD208.pdf. Acesso em: 26/11/2017.

MISSIO, F. J. Câmbio e Crescimento na abordagem Keynesiana-Estruturalista. Tese (Doutorado em Economia), Universidade Federal de Minas Gerias, Minas Gerais, 2014.

MISSIO, F. J. JAYME, F.G. OREIRO, J. L. A tradição estruturalista em economia, 2012. Disponível em:

http://joseluisoreiro.com.br/site/link/3b4c257c6943e21b64ad04a29763cb3685ea7215 .pdf. Acesso em: 18/11/2016.

OLIVEIRA, C. C; MAIA, G; MARIANO, J. O SISTEMA DE BRETTON WOODS E A DINÂMICA DO SISTEMA MONETÁRIO INTERNACIONAL CONTEMPORÂNEO. PESQUISA E DEBATE, SP, vol. 19, número 2 (34) pp. 195-219, 2008.

PALAN, Ronen. Susan Strange 1923-1998: A Great International Relations

Theorist. Review of International Political Economy, Vol. 6, no.2: 121-32. 1999 PALLUDETO, A.W.A. ABOUCHEDID, S. C. A hierarquia de moedas e a relação centro-periferia revisitada, 2014. Disponível em:

https://www.anpec.org.br/encontro/2014/submissao/files_l/i7e923374cc89126567270d9f340d65214.pdf. Acessoem: 18/11/2016.

PALMA, J.G. Structuralism. In: DUTT, A.K; ROS, J. (ed.) International Handbook of Development Economics. Cheltenham: Edward Elgar, 2008a, p. 136-143.

PRATES, D. M.; CINTRA, M. A. M. Keynes e a hierarquia de moedas: possíveis lições para o Brasil. Campinas: IE/Unicamp, out. 2007. (Texto para Discussão, n. 137)

PULCHERIO, M. C. D. T. F. O FMI e o sistema monetário e financeiro internacional: A interferência do Poder Estrutural americano. Dissertação (Mestrado em Economia Política Internacional), Instituto de Economia, Universidade Federal do Rio de Janeiro, Rio de Janeiro, 2015.

RODRÍGUEZ, O. O Pensamento da CEPAL: Síntese e Crítica. Novos Estudos CEBRAP, São Paulo n. ${ }^{\circ 16}$, pp. 8-28, dez. 1986. 
RODRÍGUEZ, O. O Estruturalismo Latino-Americano. Rio de janeiro: Civilização Brasileira, 2009.

SAAD-FILHO, A.The rise and decline of Latin American structuralism and dependency theory. In: JOMO, K.S.; REINERT, E.S. (ed.) The origins of development economics: how schools of economic thought have addressed development. London: Zed Books, 2005, p. 128-145.

\section{SANTOS, T. A TEORIA DA DEPENDÊNCIA:UM BALANÇO HISTÓRICO E}

TEÓRICO. 2012. Disponível em: file:///C:/Users/LABINFOBB10/Downloads/o_pensamento_da_cepal.pdf. Acessoem: 18/11/2016.

SERRANO, F. Do ouro imóvel ao dólar flexível. Economia e Sociedade, Campinas, v. 11, n. 2 (19), p. 237-253, jul./dez. 2002

SERRANO, F. Relações de Poder e Política Macroeconômica Americana, de Bretton Woods ao Padrão Dólar Flexível. O Poder Americano. Petrópolis: Editora Vozes, 2007.

SICSÚ, J. Políticas não-monetárias de controle da inflação: Uma proposta pósKeynesiana. In: VII Encontro da Sociedade de Economia Política, Curitiba, 2002. Disponível em:

http://www.ie.ufrj.br/moeda/pdfs/politicas_nao_monetarias_de_controle_da_inflacao. pdf. Acesso em: 26/11/2017

STRANGE, SUSAN. States and Markets. Continuum. Nova York. 1994 1967. .Debts, Defaulters and Development. Revista International Affairs no. 43.

New Look at Trade and Aid. Revista International Affairs no. 42. 1966

TAVARES, M.C.; FIORI, J.L (org.), Poder e Dinheiro: uma economia política da globalização. Petrópolis: EditoraVozes, 1997.

TAVARES, M. C. A retomada da hegemonia norte-americana. Poder e Dinheiro: uma economia política da globalização. Petrópolis: EditoraVozes, 1997.

TAVARES; M. C; MELIN, L. E. Pós-escrito 1997:a reafirmação da hegemonia norteamericana. Poder e Dinheiro: uma economia política da globalização. Petrópolis: EditoraVozes, 1997.

VERNENGO, M. Technology, Finance, and Dependency: Latin American Radical Political Economy in Retrospect. Reviewof Radical PoliticalEconomics, v. 38 , n. 4, p. 551-568, 2006. 